\title{
Subalternidade e Políticas da Diferença no Brasil: o caso das comunidades remanescentes de quilombo
}

\author{
Subalternity and Politics of Difference in Brazil: \\ the case of the quilombo remaining communities
}

\author{
André Videira de Figueiredo
}

\begin{abstract}
Resumo
O debate político-jurídico em torno das chamadas "minorias" pode ser pensado a partir de duas chaves: a da desigualdade, a apontar para a necessidade de políticas que promovam a igualdade material, e a da diversidade, que aponta para a necessidade de reconhecimento das formas particulares de ser no mundo. Neste trabalho, pretendo discutir o problema da "diferença" a partir destas duas dimensōes, colocado nos seguintes termos: como pensar em uma concepção universal da política e dos direitos que dê conta das demandas particulares e plurais dos grupos? Para tal debate pretendo lançar mão da análise das políticas públicas voltadas para comunidades remanescentes de quilombo no Brasil, tendo em vista discutir não apenas os encontros e desencontros entre o global e o local, mas também os desafios da garantia dos direitos de minorias em contextos periféricos. Pensar a questão étnica no Brasil nestes termos permite conjecturar sobre os sujeitos que as políticas de reconhecimento fazem emergir, as suas condiçōes de afirmação na política e no direito modernos e as dificuldades em torno da conjugação entre as pautas específicas dos movimentos e as demandas em torno de um projeto de tranformação da sociedade.
\end{abstract}

Palavras-chave: subalternidade, diferença, quilombos

\section{Abstract:}

The political and legal debate about the so-called "minorities" can be addressed from two different perspectives: the one of inequality, which emphasizes policies that promote material equality, and the one of diversity, which emphasizes the pursuit of recognition of different ways of living. This paper aims to discuss the issue of "difference" from these two perspectives, addressing the following problem: how can we elaborate a universal conception of politics and rights capable of addressing particular as well as plural demands from the groups? To do so, I intend to analyze Brazilian public policies directed to remaining quilombola communities, in order to discuss not only the situations in which the "global" and the "local" meet each other and the ones in which they don't, but also the 


\begin{abstract}
challenges to assuring the rights of minorities in peripheral contexts. Thinking the ethnical matter in Brazil on these terms allows us to conjecture about the subjects which emerge through recognition policies, the conditions in which they affirm themselves on modern politics and law, and the difficulties to bring together specific issues of those movements and the demands concerning a project directed to society transformation.
\end{abstract}

Keywords: subalternity, difference, quilombos.

\section{Introdução}

Neste artigo pretendo pensar o problema da "diferença", agregando duas dimensōes distintas, desigualdade e diversidade, e colocado nos seguintes termos: Como pensar em uma concepção universalista da política (e de direitos) que dê conta das demandas particulares e plurais dos grupos, muitos deles classificáveis como "minorias"? O pressuposto deste artigo, portanto, é o da busca de uma alternativa entre a multiplicidade fragmentadora e o universalismo descarnado, em uma concepção de totalidade (um projeto de emancipação política universal) que incorpore a heterogeneidade (a pluralidade de formas de ser no mundo). Para tal debate pretendo lançar mão, em primeiro lugar, do caso das comunidades remanescentes de quilombo no Brasil, tendo em vista discutir não apenas os encontros e desencontros entre o global e o local, mas também os desafios da garantia dos direitos de minorias em contextos periféricos. Em segundo lugar, buscarei articular o tema das políticas quilombolas a algumas reflexōes de um conjunto de intelectuais indianos e latinoamericanos sobre os processos políticos em contextos periféricos, articuladas em torno das categorias "subalternidade" e "colonialidade".

\section{Os limites do debate multiculturalista e a perspectiva subalterna}

O debate político-jurídico em torno das chamadas "minorias", a saber, da necessidade da afirmação de um conjunto de políticas referentes a direitos especiais de certos grupos dentro do contexto nacional, pode ser pensada a partir de duas chaves. A primeira delas é a chave da desigualdade, a apontar para a necessidade de políticas que promovam a igualdade material, ou a democratização do acesso a bens e serviços. A segunda é a chave da diversidade, a apontar para a necessidade de reconhecimento das formas particulares de ser no mundo. A cientista política norteamericana Nancy Fraser expressou esta dupla orientação na tensão entre reconhecimento e redistribuição, como proposiçōes políticas referentes a duas formas distintas de injustiça, as culturais e as econômicas, portanto a duas concepçōes de direitos, à diferença e à igualdade (Fraser, 2001, 2007a). Tal distinção de políticas e de direitos estaria referida, segundo a autora, a uma mudança de paradigmas, dos interesses de classe como motor privilegiado para a mobilização política para as diferenças culturais como mobilizadoras de identidades.

A autora, no entanto, aponta para o fato de que, para muitos grupos, injustiça cultural e injustiça econômica encontram-se imbricadas na realidade social, reforçando-se mutuamente, e que tais coletivos, portanto, evocam a natureza dupla das políticas nas democracias contemporâneas, ao mesmo tempo de reconhecimento e redistribuição (2001). Assim, grupos dilemáticos, como minorias raciais e de gênero, são exemplares do caráter integrado das demandas de redistribuição e reconhecimento: políticas redistributivas res-

\footnotetext{
${ }^{1}$ Axel Honneth oferece uma leitura alternativa à de Fraser para a emergência das políticas de reconhecimento, nāo como resultado do fracasso do projeto econômico redistributivista, mas como indicador do adensamento moral da democracia, na percepção de outras condiçōes necessárias ao reconhecimento pleno dos sujeitos, para além das liberdades civis e das condiçōes mínimas de bem estar; neste sentido, para Honneth, mesmo as políticas sociais redistributivas são, a rigor, políticas de reconhecimento (Honneth: 2003, 2007).
} 
pondem à percepção da divisão sexual e racial do trabalho como forma de exclusão econômica, enquanto políticas de reconhecimento partem da afirmação de que tanto mulheres quanto negros sofrem outro tipo de opressão, no qual elementos culturalmente considerados intrínsecos a estes grupos são avaliados depreciativamente. Esta imbricação, entretanto, impõe um dilema, na medida em que os dois tipos de injustiça exigiriam remédios cujas orientaçōes podem ser contraditórias: em um caso, trata-se de valorizar as diferenças, afirmando-as como desejáveis; em outro, trata-se de aplicar medidas para eliminá-las.

Assim, a emergência das políticas de reconhecimento, e sua relação ora conflituosa, ora complementar com as políticas de redistribuição, evoca um debate em torno de outra tensão, entre a afirmação do pluralismo das formas de ser e estar no mundo e um projeto de sociedade e de transformação social de caráter universal. Fraser resolve este dilema pela defesa de políticas de natureza "transformativa", quer sejam as de reconhecimento, cujo objetivo seria reparar o desrespeito desconstruindo diferenças culturais, quer sejam as de redistribuição, reestruturando as relaçōes materiais de produção (2001).

Para Fraser, o debate redistribuição/reconhecimento encontra-se ancorado em uma divergência filosófica entre a moralidade kantiana, ancorada na perspectiva de parâmetros universais de justiça, e a ética hegeliana, fundada no reconhecimento de formas específicas de vida boa (2007a). A autora pretende recuperar o paradigma do reconhecimento para a moralidade (em contraposição à leitura ética), como uma demanda por justiça, rompendo com o "modelo padrão de 'identidade' do reconhecimento" (2007b, pág. 116). A demanda pelo reconhecimento, nesta chave, deixa de ser pela afirmação de formas boas de ser no mundo (e das identidades referentes a elas), e passa a constituir a condição para o gozo da paridade participativa e de status igualitário. Uma solução de caráter universalista, portanto, para a qual o aporte empírico da autora, o movimento feminista, apresenta um caráter exemplar: tendo emergido, em sua "segunda onda", sob a égide da redistribuição, e passado pela culturalização de suas demandas na fase do reconhecimento, o feminismo estaria, hoje, caminhando para uma síntese das duas chaves, agora no processo de construção de um projeto político transnacional, no qual as mulheres tenham garantia de "representação" (entendida não apenas como voz política igualitária, mas também como uma releitura dos critérios para a luta por justiça).

Charles Taylor, por sua vez, aponta para as políticas de identidade como referentes a um critério de justiça que, em complemento à idéia de igual dignidade individual, aponta para o direito de permanência de formas específicas de viver no mundo. Uma concepção comunitarista da vida política, pautada na afirmação substantiva de formas específicas de vida boa, mas de caráter multicultural, baseada na afirmação da convivência de uma pluralidade destas formas. Para este autor, entretanto, tanto quanto para Fraser, as políticas de reconhecimento não estão fundadas na afirmação de que tais culturas tenham valor em si, mas na necessidade de que essas variadas formas componham um repertório amplo para a produção do Self, a partir do qual os sujeitos, por meio de suas escolhas morais, possam constituir sua identidade. 0 não-reconhecimento, ou o reconhecimento distorcido, neste sentido, afeta negativamente a formação da identidade, objetivando atribuiçōes subjetivas e produzindo uma auto-imagem depreciativa. Estamos, sem dúvida, diante da ampliação do conceito de cidadania, em relação ao modelo marshalliano, baseado no trípé dos direitos civis, políticos e sociais. Mas o que está em jogo, no fim das contas, é ainda a realização plena das subjetividades individuais. Razão pela qual o comunitarismo de Taylor acaba por incorrer em uma variação de liberalismo, a combinar objetivos comuns, liberdades individuais e respeito à diversidade (1994, 2007).

Os autores da teoria crítica do reconhecimento lograram êxito no diagnóstico da emergência de 
um novo modelo de política, tanto nos contextos nacionais quanto nos espaços transnacionais, bem como na identificação de seus pressupostos morais e filosóficos. Sua reflexão, entretanto, apresenta certa dificuldade em resolver uma das tensões mais clássicas das relaçōes sociais no mundo moderno e, por conseqüência, da própria teoria social: aquela, colocada já por Georg Simmel em seu célebre artigo sobre a vida nas cidades, entre uma concepção de modernidade fundada em valores, normas e padrões de sociabilidade universais $e$ individualistas, e formas tradicionais de ser no mundo, avessas tanto a um projeto totalizante de sociedade quanto aos espaços de manifestação das liberdades individuais. Nesta tensão, diante da ameaça dos particularismos, os autores da teoria crítica do reconhecimento acabam por optar pelo individualismo liberal. Assim, a teoria crítica do reconhecimento não dá conta da dificuldade em se romper com a narrativa eurocentrada da modernidade, do que decorre um universalismo incapaz de dar conta tanto das propostas pluralistas de sociedade e Estado, sempre reduzidas às demandas de realização dos sujeitos individuais, quanto dos desafios do reconhecimento nos contextos subalternos.

Tendo em vista estas tensōes, pretendo mobilizar uma perspectiva teórica que, gerada em tais contextos, permita pensar o debate sobre diferenças e desigualdades na América Latina em termos de um projeto universal de emancipação (bem como as dificuldades em torno de sua elaboração). Tal perspectiva teórica, encampada pelos intelectuais indianos do coletivo Estudos Subalternos na década de 1980 e pelos descolonais latinoamericanos a partir dos anos 1990, constitui um exercício de crítica às formas hegemônicas de interpretação da modernidade, repensando as Ciências Sociais a partir da percepção de uma "geopolítica do conhecimento".

Isto significa, em primeiro lugar, elaborar uma reconstrução autóctone e crítica das narrativas locais e nacionais, pela ressignificação do papel histórico e político dos sujeitos subalternos, aque- les tomados pelo pensamento europeu como "pré-modernos" e "pré-políticos" (Guha, 1983). Em segundo lugar, trata-se de pensar, para além dos contextos nacionais, o próprio processo de construção da modernidade, até então lida, do ponto de vista privilegiado do pensamento europeu, como evento universal que a todos dispōe em uma linha temporal (Chakrabarty, 2008). Nesta chave, as teorias periféricas apontam não apenas para a possibilidade de afirmação de "modernidades alternativas", heterônomas, como no caso da Índia (Chakrabarty, 2008; Chatterjee, 2004), como para a percepção do contexto latinoamericano como a outra face da modernidade, marcada desde seu início por uma padrão etnicorracial de dominação (Quijano, 2009). Finalmente, tais autores permitem uma crítica ao próprio processo de construção da teoria social, na tensão entre a pretensão de universalidade das ciências sociais e a sua radicação local, leia-se européia, apontando para as possíveis contribuiçōes dos "saberes subalternos" para a teoria social, ou ainda, explorando as "energias descoloniais" que, desde o início da modernidade, oferecem outras versões para a narrativa moderna, versões que foram vencidas no processo de dominação colonial. (conhecimentos que foram vencidos no processo de dominação colonial). Assim, para estes autores, provincializar a teoria social (o que corresponde a provincializar a própria Europa como perspectiva universal) leva a que se repense a própria construção totalizante do edifício das ciências sociais.

Pensar a questão étnica no Brasil a partir deste aporte teórico permite conjecturar sobre os sujeitos que as políticas de reconhecimento fazem emergir, as suas condiçōes de afirmação na política e no direito modernos e as dificuldades em torno da conjugação entre as pautas específicas dos movimentos e as demandas em torno de um projeto de transformação da sociedade. Será preciso, portanto, deitar um olhar informado por estas reflexões sobre as políticas voltadas para as comunidades remanescentes de quilombo. 


\section{As políticas quilombolas}

A emergência das comunidades quilombolas como sujeitos coletivos de direitos se deu a partir da Constituição de 1988, com a garantia, aos "remanescentes de comunidades de quilombo", do título de propriedade das "terras que ocupam" (artigo 68 do Ato da Disposiçōes Constitucionais Transitórias). Durante a década de 1990, um conjunto de atores se mobilizou no sentido de produzir uma interpretação do dispositivo constitucional que definisse aquilo que a Constituição não define: quem são os sujeitos deste direito à terra, e como tal direito é garantido. Assim, consolidou-se a definição dos "remanescentes" como grupos étnicos, portanto como sujeitos coletivos de direito constituídos a partir de suas próprias práticas de definição das fronteiras de pertencimento e não-pertencimento. No mesmo sentido, a categoria "terra ocupada" foi definida a partir da idéia de território, ou seja, espaço apropriado simbolicamente, neste caso a partir de práticas coletivas de reprodução material, social e cultural dos grupos. Tais práticas se teriam constituído a partir de regimes jurídicos próprios, definindo o território como terra de uso comum. Tal direito seria então garantido, formalmente, através da emissão de títulos coletivos, em nome de associaçōes, com cláusulas de indivisibilidade, impenhorabilidade e inalienabilidade.

Em 2003, a ascensão do Partido dos Trabalhadores ao governo federal consubstanciou-se, na questão quilombola, em uma extraordinária ampliação do rol de direitos quilombolas e, portanto, das políticas que Ihes correspondem. Em 2004, o governo federal lançou o programa interministerial Brasil Quilombola, cuja finalidade era "coordenar as açōes governamentais para as comunidades remanescentes de quilombos por meio de articulaçōes transversais, setoriais e interinstitucionais". Envolvendo 17 ministérios e cinco secretarias, o programa, organizado em torno de quatro eixos (regularização fundiária, infra-estrutura e serviços, desenvolvimento e participação) articulava tanto políticas de redistribuição quanto políticas de reconhecimento.

Apesar desta progressiva ampliação das concepçōes de direitos e políticas, o direito ao território permanece como núcleo central dos debates e das mobilizaçōes em torno desta identidade étnica, e isto por pelo menos três razōes. Em primeiro lugar, porque a própria afirmação deste sujeito de direitos se dá, no âmbito constitucional, na garantia de um direito fundiário. Segundo, porque é a questão fundiária aquela que mais fortemente mobiliza as iniciativas contrárias à política quilombola, justamente por conta dos interesses em torno da propriedade da terra. Finalmente, a garantia da permanência em seus territórios na forma de titulação coletiva é condição sine qua non para a própria existência da comunidade, agora protegida da conversão da terra em mercadoria e, portanto, base material para a afirmação dos demais direitos e políticas.

Além da ampliação das políticas, o primeiro governo Lula foi marcado, no que diz respeito ao tema, pela recepção e formalização da interpretação ressemantizada do artigo 68 do ADCT, qual seja, aquela produzida pelos movimentos sociais, antropólogos e Ministério Público, segundo a qual o direito quilombola à terra é de natureza coletiva, dizendo respeito a um território culturalmente constituído, e a ser definido, caso a caso, a partir dos procedimentos de auto-atribuição de cada comunidade, tanto de sua identidade quilombola, quanto dos limites materiais de seu território.

A despeito dos avanços nas políticas, tanto no que diz respeito ao conjunto de direitos quanto à interpretação da identidade e da territorialidade quilombola (e, portanto, também dos procedimentos para a consecução de tais políticas), não foram contabilizados avanços substanciais no que diz respeito ao placar das titulaçōes². A Secretaria

${ }^{2}$ Utilizei-me, aqui, das avaliaçōes do Instituto de Estudos Socioeconômicos (INESC), publicadas nas Notas Técnicas números 139 e 168, e de dados informados pelo INCRA em «http://www.incra.gov.br/estrutura-fundiaria/quilombolass. 
Especial de Políticas de Promoção da Igualdade Racial (SEPPIR) contabiliza, hoje, quase cinco mil comunidades quilombolas identificadas, sendo 2.697 destas certificadas pela Fundação Cultural Palmares, com 1532 processos de regularização fundiária abertos no Instituto Nacional de Colonização e Reforma Agrária (INCRA), o órgão do Ministério de Desenvolvimento Agrário responsável pela titulação dos territórios quilombolas. Entretanto, até hoje foram emitidos apenas 210 títulos de propriedade, relativos a 151 territórios e 241 comunidades.

Um olhar mais detalhado sobre os números revela que, a despeito dos avanços a partir de 2003, não há discrepância entre o número de titulaçōes nos governos do PSDB e aquele relativo aos dois primeiros governos do PT. A atuação do Governo Federal parece-nos ainda mais tímida neste período, quando percebe-se que cerca de $80 \%$ dos títulos emitidos foram resultado da atuação dos Institutos de Terra estaduais. Assim, entre 1995 e 2002 foram emitidos 44 títulos, dos quais 18 foram emitidos pelo Governo Federal. Entre 2003 e 2010, 78 títulos foram emitidos, destes apenas 17 por atuação do Governo Federal.

Em relação ao governo Lula, o governo Dilma tem apresentado um avanço no significativo no quadro das titulaçōes: entre 2011 e 2015, 88 títulos foram emitidos, dos quais 60 foram de responsabilidade do INCRA. Entretanto, em que pese o avanço a partir de 2011, o esperado salto nas titulaçōes, resultado da inflexão das políticas quilombolas a partir de 2013, não ocorreu.

Muito se tem discutido acerca das razōes da lentidão nas titulaçōes. Se, por um lado, o decreto $\mathrm{n}$ - 4887/03 constituiu um avanço na política fundiária quilombola, no que tange à recepção, em uma norma federal, da interpretação ressemantizada de comunidades e territórios quilombolas (ainda que na forma de decreto, e não de lei), por outro lado as instruçōes normativas internas ao INCRA, responsáveis pela regulação da atuação do órgão no tema, constituem, hoje, verdadeiros entraves administrativos à consecução das titulaçōes (INESC, 2010, pág. 07). Assim, por exemplo, a exigência de que uma comunidade receba certificado da Fundação Cultural Palmares como condição para a abertura do processo de titulação, em que pese a simplicidade do procedimento, corre o risco de produzir entraves para grupos que nunca se preocuparam em pedir a certificação da FCP, posto que seu processo de titulação foi iniciado quando o órgão não tinha esta atribuição ${ }^{3}$. Além disto, a avaliação do INESC aponta para a opção em se titular comunidades em terras devolutas dos estados, dados os conflitos que incidem em torno da desapropriação das terras particulares com títulos de propriedade válidos. Assim, de quarenta e quatro decretos desapropriatórios emitidos desde 2006, apenas três deles redundaram em titulação, a saber, aqueles relativos às comunidades de Família Silva, Colônia São Miguel e Preto Forro. Some-se a este problema a validade de tais decretos, de apenas dois anos, em um contexto de morosidade da justiça.

Não bastasse sua baixa eficácia, os dispositivos da política fundiária para quilombos encontram-se, hoje, sob grave ameaça. Desde 2004, tramita no Supremo Tribunal Federal uma Ação Direta de Inconstitucionalidade contra o decreto no 4887, movida pelo Partido Democratas, e que já conta com voto desfavorável de seu relator, o Ministro Cezar Peluso. Enquanto o texto da ADIN levanta o argumento de que o decreto do Poder

\footnotetext{
${ }_{3}$ Tal entrave se manifestou no caso da comunidade de Santa Rita do Bracuí, no Rio de Janeiro. A Fundação Cultural Palmares, que até 2003 tinha como atribuição conduzir o processo de identificação, delimitação e titulaçăo dos territórios quilombolas (sendo o ato de titulação, entretanto, de competência do INCRA), passa, a partir do novo decreto, a ter como atribuição emitir um certificado de auto-reconhecimento da condição quilombola do grupo. Em 1998, quando se iniciou o processo de titulação da comunidade do Bracuí, ainda sob a competência da FCP, tal certificação não existia. Em 2012, ao ser questionada pela própria comunidade dos motivos da morosidade de seu processo de titulação, a superintendência do INCRA no Rio de Janeiro atribuiu tal demora à inexistência desta certificaçāo, cuja exigência só passou a vigorar a partir da Instruçāo Normativa no 49 , de 2008 .
} 
Executivo usurpa as atribuiçōes do Legislativo, um Projeto de Lei, hoje arquivado, e um Projeto de Decreto Legislativo, ambos de autoria do deputado Valdir Colatto, reproduzem a interpretação restritiva do artigo 68-ADCT, como à época do governo Fernando Henrique Cardoso.

Dentre as políticas propostas pelo Governo Federal a partir de 2004, com o Programa Brasil Quilombola, aquelas relativas à educação diferenciada parecem ser as que assumiram maior destaque. Modalidade do Ensino Básico desde 2010, essa proposta de educação foi elaborada, na Lei de Diretrizes Curriculares Nacionais para a Educação Básica, em forte homologia com a Educação Escolar Indígena. Tanto quanto esta, a educação escolar quilombola é definida, pela lei, como constituída a partir de uma "pedagogia própria", condizente com a "especificidade étnico-cultural" dos grupos. Esta homologia com a questão indígena está presente desde os primórdios da disputa em torno das interpretações sobre o que é quilombo, e informou o processo de ressemantização do dispositivo constitucional, em boa medida em razão da participação de antropólogos indigenistas neste debate. Entretanto, enquanto no caso indígena as DCNs fazem referência à necessidade de reconhecimento de uma "realidade própria" e de um "ordenamento jurídico próprio" como condição para uma educação "intercultural e bilíngüe", no caso quilombola a lei faz referência apenas à necessidade de se considerar a "diversidade cultural".

Neste processo, o movimento quilombola conduziu suas próprias discussões acerca de suas demandas em torno da educação escolar quilombola. Vejamos o que diz um dos documentos resultantes deste debate, a Carta de Princípios da Educação Escolar Quilombola, publicada pela Comissão Estadual de Comunidades Quilombolas de Pernambuco em março de 2008. Podemos distinguir três sentidos em torno das demandas do movimento quilombola por uma educação própria. Em primeiro lugar, uma educação quilombola teria um caráter eminentemente político, constituindo-se de iniciativas que privilegiassem o fortalecimento comunitário e territorial, no entendimento da escola como um espaço de resistência e afirmação da identidade. Em segundo lugar, esta é uma política entendida pelo movimento como de reconhecimento cultural e étnico, e uma educação escolar quilombola deve ser construída em conformidade com as práticas organizativas e culturais dos grupos; assim, organização do espaço e do tempo, historicidade, formas de ensinar e aprender, festas, práticas alimentares, dentre outros elementos da vida dos grupos devem ser incorporados nos conteúdos e processos educacionais, e pautar a construção de currículos e material didático. Como apontou em uma fala uma liderança quilombola do Rio de Janeiro, professor é um problema quando não tem, e pode ser um problema quando tem. Finalmente, um terceiro aspecto diz respeito ao que Fraser chama de paridade participativa, e aponta para o entendimento da participação autônoma dos grupos como condição para a educação quilombola, quer seja na construção de material didático e currículo, quer seja na participação em conselhos ou na elaboração da legislação sobre o tema.

Em 2012, o Ministério da Educação aprovou as Diretrizes Nacionais para a Educação Escolar Quilombola, recepcionando boa parte das demandas dos movimentos em torno desta modalidade de ensino. Assim é que, segundo as DCNs, os currículos, materiais didáticos, o espaço escolar, a merenda, o calendário, o Projeto Pedagógico devem incorporar elementos da realidade local, e constituírem-se como elementos de resistência comunitária e étnica. É, entretanto, no eixo da participação que as DCNs quilombolas não contemplam as demandas do movimento. A demanda por participação na produção das políticas converte-se em direito à consulta em todas as decisões que atinjam às comunidades, em referência direta à Convenção 169 da Organização Internacional do Trabalho. Além disso, ao invés de atrelar a educação quilombola à presença de professores quilombolas, como no caso da questão indígena, as DCNs postulam que os professores deverão ser "preferencialmente qui- 
lombolas", prevendo concursos públicos nos quais será exigido o conhecimento acerca da questão, e não a pertença comunitária.

No plano da implementação das políticas, os avanços são ainda mais tímidos, e se consubstanciam mais em uma política de redistribuição do que em uma política de reconhecimento. A princípio, impressiona o crescimento considerável do número de escolas declaradas quilombolas, de 364 em 2004 (ano no qual o Censo Escolar inventariou pela primeira vez este tipo de unidade escolar), para 1.912 escolas em 2002. Tal crescimento pode ser explicado, em parte, em razão da consideração, a partir de 2007, da presença de "educação quilombola" para o repasse de recursos do Fundo de Manutenção e Desenvolvimento da Educação Básica e de Valorização dos Profissionais da Educação (Fundeb) para os municípios. Tal destinação de recursos, entretanto, não está vinculada à sua aplicação nas escolas em terras de quilombo, ou que atendam a alunos quilombolas. Neste sentido, a destinação de recursos do FUNDEB para escolas quilombolas, embora tenham dado destaque à questão nos contextos municipais, não implicaram a implementação de uma política efetiva de educação quilombola, ou ainda a ampliação da participação das comunidades, mas, ao contrário, em agenciamento por dos agentes municipais do movimento e da representação (Arruti, 2009).

Segundo Arruti (op. cit.), ao contrário das políticas fundiárias, as políticas de educação voltadas para comunidades quilombolas constituem, hoje, apenas uma extensão das políticas universais de combate à pobreza: construção de salas de aula, distribuição de material didático, extensão do programa Luz para Todos. Trata-se, não há dúvida, de uma atenção diferenciada às escolas que atendem a comunidades quilombolas, mas não de uma proposta de educação diferenciada. Assim, segundo Arruti, "o seu reconhecimento [nas políticas de educação] como segmento diferenciado da sociedade nacional tende a se limitar à constatação de que mesmo entre os pobres e miseráveis do país há uma camada ainda mais desprivilegiada" (Arruti, op. cit.).

\section{Os quilombolas como subalternos}

Embora os direitos quilombolas tenham sido afirmados no plano constitucional, o próprio artigo 68-ADCT não explicita os critérios para a definição do sujeito de tais direitos. Tal definição de sujeitos e direitos se deu de forma conjuntural, em primeiro lugar pela atuação de um conjunto de mediadores (atores do mundo do direito, especialmente os vinculados ao Ministério Público Federal, antropólogos, militantes, lideranças de comunidades negras rurais), logo em seguida oficializada tanto na atuação dos Institutos de Terra estaduais, ainda na década de 1990, como também pelo governo federal, pelo decreto $4887 / 03$, que passou a informar as políticas voltadas para quilombos. Entretanto, como vimos, essa é uma garantia precária, cujos riscos se consubstancializam na ADIn movida contra o decreto, bem como nos projetos de lei que tramitam no Congresso Nacional. Trata-se, portanto, antes de qualquer coisa, de um objeto de disputas, ora na arena propriamente política, ora na arena judiciária. Neste sentido, a afirmação dos quilombolas como sujeitos de direitos étnicos especificamente territoriais se dá segundo a lógica da "governamentalidade".

Como objeto de políticas de diferença, os quilombos estão na esfera do que Partha Chatterjee chama de "política dos governados" (op. cit.). Chatterjee elabora esse espaço da política a partir da tensão, segundo ele presente na política indiana, entre o mundo homogêneo da cidadania, do Estado e dos direitos, que ele chama de "sociedade civil", e o mundo heterogêneo da governamentalidade, do governo e das relações políticas, que chama de "sociedade política", espaço de controle social das populaçōes. A "política dos governados", neste sentido, corresponde a este último espaço, onde o acesso dos grupos aos direi- 
tos depende tanto de sua capacidade de se mobilizar e mobilizar outros atores, quanto de uma conjuntura política favorável. Assim, a indefinição política a que estão submetidas as interpretaçōes em torno do artigo 68-ADCT e sua definição no espaço do político, torna os direitos quilombolas sujeitos aos ventos da política e a todo o tipo de ataque. Do mesmo modo, o processo de expansão dos direitos quilombolas se deu no plano da governabilidade, na construção de políticas de governo, e não no plano do Estado, na construção de uma legislação em torno do tema: no debate em torno do Estatuto da Igualdade Racial, as expectativas em torno da questão quilombola foram frustradas, e o texto da lei se resumiu a repetir o enunciado constitucional.

Chatterjee ajuda a entender a emergência dos sujeitos subalternos do ponto de vista do diagnostico da sua operação, num marco diferente daquele postulado por Ranajit Guha: não como sujeitos políticos revolucionários, mas como os sujeitos das políticas públicas. Neste sentido, Chatterjee mostra como as políticas públicas não se constituem como um espaço onde se faz cessar a vida política, mas como lugar onde ela se constrói, constituindo uma nova plataforma de onde os sujeitos podem articular seus interesses e valores. Assim, apesar da fragilidade da construção dos direitos quilombolas nos últimos anos, o que acaba por transparecer nas tentativas sistemáticas de sustar os efeitos do decreto 4887, podemos dizer que foi no campo das disputas pelas políticas de governo que o movimento quilombola construiu sua força, $e$ que a questão quilombola ganhou destaque e reconhecimento no plano nacional, tanto no que diz respeito ao mundo da opinião quanto no que tange á sua constituição como objeto de pesquisa e reflexão acadêmica.

Se considerarmos os casos de demandas de comunidades quilombolas específicas, a condição subalterna destes grupos pode se manifestar com mais força. Isto fica claro particularmente nos casos em que os quilombos encontram sua oposição justamente em outro braço do estado, militarizado, como nos casos de Rio dos Macacos (BA), da Ilha da Marambaia (RJ) e dos quilombos de Alcântara (MA). Nestes casos, nos quais os principais contendores das comunidades são as forças armadas (a Marinha, nos dois primeiros casos, e Aeronáutica no terceiro), a subalternidade da construção dos sujeitos políticos se manifesta não apenas no fato de que as lesōes de direitos são infligidas pelo próprio Estado que deveria garanti-los, mas também porque a garantia efetiva dos direitos destes sujeitos se dá em função de uma articulação local, pela constituição de uma rede de apoio. Assim, radicaliza-se o sentido da subalternidade, como a entende Gayatri Spivak (op. cit.): aquele que, por suas condiçōes materiais (e simbólicas) está alienado tanto do mercado e da distribuição de riquezas quanto da representação política, portanto da possibilidade de se erguer como uma voz subalterna.

O debate em torno dos direitos étnicos no Brasil permite modular a dualidade de Chatterjee entre as séries restritas e as séries irrestritas, entre o mundo da soberania e da sociedade civil e mundo do governamental e da sociedade política. Por um lado, é perceptível que os quilombolas, dadas as incertezas em torno das garantias constitucionais de seus direitos, transitam pelo mundo do governamental, dos arranjos possíveis, das negociaçōes políticas e da conquista dos apoios, em contraposição ao mundo da sociedade civil, dos direitos iguais e das garantias constitucionais. Por outro lado, esta sua condição contrasta com o caso dos povos indígenas, cujos direitos estão garantidos em um capítulo da Constituição que explicita os significados em torno dos termos de sua aplicação. Podemos, assim, afirmar a existência de um meio termo entre o mundo da soberania e da sociedade civil igualitária e o mundo da governabilidade e da sociedade política heterogênea: o espaço da afirmação constitucional do direito à diferença, o mundo do reconhecimento, no qual a heterogeneidade seja incorporada à construção constitucional da cidadania, ampliando a 
compreensão dos direitos universais ${ }^{4}$. Assim, nem toda a heterogeneidade pertence ao domínio do governamental, e algumas delas ganharam 0 status de direitos de minorias ${ }^{5}$, assim como nem toda a gestão de tais diferenças constitui exercício de controle social, ou exercício de poder, embora esta ainda seja a tônica na questão quilombola.

Coloca-se, neste sentido, outro problema para o debate em torno da emergência dos sujeitos subalternos, relativo ao modo como estes se articulam à narrativa totalizante do direito e da Constituição. A perspectiva teórica subalterna oscila, neste caso, entre a idéia, ainda moderna, de que a pluralidade e a heterogeneidade característica do mundo moderno (inclusive de seus contextos periféricos) deve encontrar um termo de totalização, uma síntese possível em torno de um projeto global de política e de emancipação, e a idéia pós-moderna de fragmentação e pluralidade sem síntese. Para Dipesh Chakrabarty (op. cit.), em explícita oposição ao pensamento pós-moderno, o discurso totalizante e homogêneo do Ocidente moderno (o que chama de "história 1") deve incorporar, ou deve-se permitir turbar, pelos discursos heterogêneos e fragmentários das realidades locais e das formas específicas de vida dos povos, daquilo que chama de "histórias 2", mas sempre tendo em vista a produção de uma síntese, um último termo. Trata-se, nos termos do poeta martinicano Aimé Cesaire, de uma concepção de universal "depositário de todo o particular, depositário de todos os particulares, aprofundamento e coexistência de todos os particulares" (apud Castro-Gómez e Grosfoguel, 2007). Em contraposição, para Gayatri Spivak não existe síntese possível para estes sujeitos subalternos e fragmentários, e as tentativas de falar de um sujeito plural acabam reprisando o enunciado de um sujeito europeu, de um indivíduo genérico e totalizado.
Spivak aponta, assim, para a necessidade de vocalização do próprio sujeito subalterno, de cada um dos sujeitos subalternos, e portanto da impossibilidade do intelectual expressar essa totalidade em termos de uma síntese teórica (ou analítica).

Nesta tensão, podemos dizer que os sujeitos subalternos da política de Partha Chatterjee incorporam a primeira possibilidade: se é verdade que estes sujeitos são heterogêneos e plurais em suas demandas, e que o contexto no qual se inserem é uma modalidade daquilo que Chakrabarty chama de "histórias 2" (versões possíveis e plurais da narrativa moderna e de seus personagens), por outro lado esta é uma narrativa moderna, na medida em que responde às expectativas em torno de um projeto de sociedade e de combate às injustiças sociais. A incorporação das conquistas do mundo da política (e das políticas) no repertório de direitos de uma sociedade (ainda que, por vezes, de forma precária, como vimos) aponta para o fato de que estas narrativas heterogêneas fazem parte da história universal da construção da cidadania.

Na leitura dos autores descoloniais latinoamericanos (Mignolo, 2003; Castro-Gómez e Grosfoguel, 2007), este universalismo subalterno traria consigo o potencial para a crítica à colonialidade que marcou o processo de construção do mundo moderno/capitalista/ocidental: um padrão etnicorracial de dominação que, tendo sido criado na relação entre povos europeus e americanos, foi mundializado, convertendo-se em uma geopolítica do poder. Estaria guardada na América Latina, portanto, a potencialidade para explorar as "energias descoloniais" de narrativas contra-hegemônicas que, coetâneas da própria modernidade, não lograram êxito em se impor na construção do discurso moderno. A perspectiva latinoamericana apresentaria, portanto, vantagens em relação à indiana para

\footnotetext{
${ }^{4}$ Em alguns casos implica mesmo a ampliação de certos direitos universais, como a participação, afirmada no direito de consulta prévia e informada aos povos tribais sobre qualquer tema que afete seus modos de vida, constituindo uma forma de acesso a práticas particulares de democracia direta.

${ }^{5}$ Se é verdade que em boa parte estes direitos estão sendo formulados no âmbito do governamental, por outro lado o judiciário (ou ainda, a dimensão jurídica) tem se constituído lugar de onde emergem (ou se irradiam) ondas afirmativas, a exemplo do julgamento das cotas no STF. Além disso, os diplomas e as cortes internacionais colaboram para esta progressiva judicialização da política da diferença.
} 
esta crítica a esta geopolítica do poder: modernos há tanto tempo quanto a modernidade, não somos um caso de "modernidade alternativa", mas o outro lado da moeda moderna, palco onde a colonialidade foi construída como marca para a construção do mundo moderno, e espaço em potencial para a elaboração de uma proposta de modernidade sem colonialidade.

Desta perspectiva, o multiculturalismo e as políticas de reconhecimento podem ser interpretados como apenas mais um capítulo da história das relaçōes modernas de colonialidade, não apenas em razão da sua ênfase liberal na realização do indivíduo, como vimos, mas em razão de seu caráter domesticador das diferenças e acessório ao projeto capitalista para o "terceiro mundo" (Walsh, 2009). Assim, em que pese a legitimidade da demanda pelas formas próprias de ser no mundo, quando elas se colocam nos marcos do multiculturalismo, ou elas se resumem à realização plena do Self, ou terminam na pauta particularista. Em contraposição ao multiculturalismo como proposta colonial, Catherine Walsh propõe que as políticas da diferença em contextos subalternos sejam pensada a partir da chave da interculturalidade, cujo pressuposto está na possibilidade de refundar a vida social (suas bases jurídicas, suas formas de fazer política, sua relação com a natureza e com a terra, etc.) a partir do reconhecimento da horizontalidade entre todas as diferentes e conviventes formas de estar no mundo. Ao analisar a militância indígena aymará em torno da educação, na Bolívia (particularmente na militância de Eduardo Nina Quispe) Esteban Ticona Alejo (2010) aponta que a defesa do ensino na língua aymará não tinha por pressuposto o direito dos indígenas à valorização de sua língua como repertório cultural para a construção de uma identidade diferenciada, mas a percepção da diversidade linguística como condição para refundar a nação boliviana em bases plurinacionais e interculturais. Assim, considerando que a nação boliviana fora fundada sob bases culturais, históricas e linguísticas de origem hispânica (e que a educação indígena em espanhol se prestava a esta construção colonial), era preciso refundar a nação, agora sob bases hispânicas, aymarás, quechuas, guaranis, entre outras. Mais que isto, refundar a sociedade boliviana sob bases interculturais constitui o caminho para a construção de uma sociedade futura pluriétnica e transnacional, rompendo com as fronteiras dos Estados, e reconstituindo a territorialidade de "Los Cuatro Suyos", os antigos marcos do império inca, retomando, como construção moderna, o que Mariátegui (2005) chamava de "a tradição mais profunda" dos povos incaicos. A proposta intercultural de reconhecimento da diversidade étnica, neste sentido, constitui um retorno à universalidade, para além dos próprios marcos do Estado-Nação, permitindo escapar do particularismo.

Neste sentido, a observação da política quilombola nos coloca como questão a forma como as demandas destes grupos se inserem ou não em uma proposta subalterna e descolonial de política e direito. Que síntese a questão quilombola permite produzir, ou em que síntese ela se insere? Como, na propositura de uma política de reconhecimento étnico que cada vez mais é pensada de forma a integrar não apenas concepçōes distintas de direitos, mas também uma pluralidade de grupos, produzir uma explicação para esta emergência que não precise se resumir ao status ou à dignidade dos sujeitos individuais, ou aos recursos para a construção do self, e que possam, efetivamente, dar conta da construção de uma narrativa totalizante? Tais questōes nos levam à percepção de que, no caso brasileiro, as políticas de reconhecimento étnico ainda não caminharam nesta direção, e a questão quilombola aponta para estas tensōes. Elaborar esta crítica, entretanto, não nos deverá "puxar para trás", para - abandono da pauta da diferença, mas nos "empurrar para a frente", para experimentos de formulação da pauta da diferença em termos interculturais, e não multiculturalistas. 
No campo fundiário, a garantia constitucional da territorialidade quilombola foi o resultado, por um lado, da organização das demandas de comunidades negras rurais do Norte e do Nordeste do país pelo reconhecimento de formas de apossamento coletivo não previstas nas políticas agrárias até aquele momento. Por outro lado, a formulação do dispositivo foi resultado também dos agenciamentos do movimento negro urbano em torno dos sentidos da questão racial em 1988, centenário da abolição, entendido como momento oportuno para a institucionalização de dispositivos anti-racistas. Assim, é como fruto tanto do desconhecimento em torno das demandas concretas dos grupos, quanto dos significados agenciados em torno da categoria "quilombo", que o artigo 68-ADCT afirma o direito à propriedade da terra para "remanescentes de comunidades de quilombo" (Arruti, 2006). Nos quase vinte anos da questão quilombola no Brasil, os atores que se mobilizaram neste cenário pouco avançaram tanto no que diz respeito aos grupos sobre os quais deveriam incidir tais direitos, aqueles entendidos como ocupantes das "terras de preto", quanto no que diz respeito à forma de titulação, em nome de uma associação. A luta quilombola pela terra, neste sentido, não evocou formulaçōes que pudessem dar conta das demandas de outros grupos que compartilhassem com os quilombolas de concepçōes de terras de uso comum. Por conseqüência, a luta pela territorialidade quilombola (e indígena) ainda não fez emergir, na sociedade civil brasileira, um debate mais amplo, em torno do direito à terra, para além dos direitos individuais, em direção a uma alteração do regime da propriedade no direito brasileiro, acolhendo modalidades coletivas de propriedade da terra, no reconhecimento jurídico a territorialidades e regimes de uso próprios aos grupos ${ }^{6}$.

É curioso notar que em parte, o dispositivo constitucional e sua interpretação resultam de concepçōes de territorialidade que se constituíram como formas de modernidade heterônomas na metade do século XIX, resistências subalternas à emergência do moderno mercado de terras, conseqüência da promulgação da Lei de Terras de 1850, e que foram recuperadas como demanda jurídica dos movimentos sociais na década de 1980. Construtos modernos, cujas energias descoloniais foram recuperadas por Alfredo Wagner Berno de Almeida na construção da categoria "terra de uso comum", redução sociológica das várias formas pelas quais os grupos nomearam seus regimes jurídicos próprios ("terras de preto", "terras de santo", "terras de índio", etc.). Entretanto, a despeito desta origem semântica, a luta pela territorialidade quilombola não evocou formulaçōes mais amplas, que pudessem dar conta daquelas demandas originais, em um caminho de volta para a possibilidade de uma síntese em torno do direito coletivo à terra, que pudesse agregar demandas distintas como as de quilombolas, indígenas, sem terra, atingidos por barragens, caiçaras, etc.

Do mesmo modo, a demanda por educação quilombola, como vimos, em forte homologia com a questão indígena, não vem sendo pensada como elemento para a crítica aos pressupostos da construção do conhecimento na sociedade brasileira, mas como uma demanda por reconhecimento das formas próprias dos grupos de fazer, ensinar e aprender, e como elemento político de resistência dos grupos na afirmação de sua identidade e de seu território. Nesta chave, a educação quilombola constitui elemento fundamental tanto para a afirmação da identidade étnica dos grupos, quanto para a construção plena das subjetividades, pela garantia de um repertório cultural para a construção do respeito. Trata-se, portanto, de uma demanda por educação diferenciada, mas não por uma educação intercultural, como no caso aymará. Esta tensão entre um projeto local de educação diferenciada e um modelo nacional de ensino é sentida, por vezes, pelas próprias co-

\footnotetext{
${ }^{6}$ Apesar do avanço, na década de 1980, na proposição de dispositivos que garantissem os direitos coletivos, tanto de ordem material, quanto processual.
} 
munidades, num contexto no qual as avaliaçōes internas e externas ao sistema de ensino pedem conteúdos universais. Neste sentido, a política de reconhecimento multiculturalista em um ambiente no qual se pedem conteúdos universalistas, cria desafios, e aponta para a importância de se pensar a educação étnica de forma intercultural, ou seja, tendo em vista mudar tais padrōes universais de avaliação (provas, concursos, etc.).

A criação, em 2007, da Política Nacional de Desenvolvimento Sustentável dos Povos e Comunidades Tradicionais (PNPCT), aponta para a possibilidade de agregar grupos e identidades distintas em torno da demanda por direitos territoriais, sociais, ambientais, econômicos e culturais, e, quem sabe, repensar, a partir destes grupos, o próprio modelo de desenvolvimento nacional. Do mesmo modo, a lei 11645/08, que cria a obrigatoriedade de inclusão de conteúdos de histórias e culturas indígenas e afro-brasileiras na Educação Básica, lança as bases para se repensar a construção do conhecimento escolar de toda a sociedade brasileira. Em que pese tratar-se de soluções vindas ainda do campo das políticas, e portanto externas às próprias comunidades, podem apontar para a possibilidade de construção de uma narrativa dos "povos tradicionais" que se incorpore à narrativa da sociedade brasileira, em um caminho para que os grupos étnicos, finalmente, abandonem sua condição de grande Outro.

\section{Bibliografia}

ALEJO, Esteban Ticona. Saberes, Conocimientos y Prácticas Anticoloniales del Pueblo Aymara-Quechua en Bolivia. Plural, La Paz, 2010.

ALMEIDA, Alfredo Wagner Berno de. "Terras de Preto, Terras de Santo, Terras de Índio - uso comum e conflito". In HÁBETTE, J.; CASTRO, Edna (org.). Na Trilha dos Grandes Projetos. Belém, NAEA/UFPA, 1989.

ARRUTI, José Maurício. Mocambo: antropologia e história do processo de formação quilombola. Bauru, Edusc, 2006.

ARRUTI, José Maurício. "Notas sobre as iniciativas federais em educação no contexto das políticas públicas para quilombos". In Secretaria de Estado da Educação
(Org.). Educação escolar quilombola: Pilōes, Peneiras e Conhecimento Escolar. Curitiba, Secretaria de Estado da Educação, 2009.

BARTH, Fredrik. "Os Grupos Étnicos e Suas Fronteiras" in O Guru, o Iniciador e Outras Variaçōes Antropológicas. Rio de Janeiro, Contracapa, 2000.

CASTRO-GÓMEZ, Santiago y GROSFOGUEL, Ramón (eds.). El giro decolonial: reflexiones para una diversidad epistémica más allá del capitalismo global. Bogotá, lesco-Pensar-Siglo del Hombre Editores, 2007.

CHAKRABARTY, Dipesh. Al margen de Europa. Madrid, Ensayo, 2008.

CHAKRABARTY, Dipesh. "Una pequeña historia de los estúdios subalternos". In shttp://www.desclasificacion.org/ pdf/Estudios_Subalternos_\%20Trad_raul_rodriguez.pdf

CHATTERJEE, Partha. Colonialismo, modernidade e política. Salvador, EDUFBA, 2004.

FIGUEIREDO, André Videira de. O Caminho Quilombola: sociologia jurídica do reconhecimento étnico. Curitiba, Appris, 2011.

FRASER, Nancy. "Da redistribuição ao reconhecimento? Dilemas da justiça na era. pós-socialista". In Souza, Jessé (Org). Democracia hoje. Brasília, UnB, 2001.

FRASER, Nancy. "Mapeando a Imaginação Feminista: da redistribuição ao reconhecimento e à representação". In Revista de Estudos Feministas, vol. 15, no․ 2, Florianópolis, maio/ agosto de 2007.

FRASER, Nancy. "Reconhecimento sem Ética?". In Jessé e Mattos, Patrícia (orgs.) Teoria Crítica no Século XXI. São Paulo, Annablume, 2007(b).

GUHA, Ranajit. Elementary Aspects of Peasant Insurgency in Colonial India. Delhi, Oxford University Press, 1983.

HONNETH, Axel. Luta por Reconhecimento: a gramática moral dos conflitos sociais. São Paulo, Ed. 34, 2003.

HONNETH, Axel. "Reconhecimento ou Redistribuição? A mudança de perspectivas na ordem moral da sociedade". In Jessé e Mattos, Patrícia (orgs.) Teoria Crítica no Século XXI. São Paulo, Annablume, 2007.

INESC. "Orçamento quilombola: entre o previsto e o gasto". Nota Técnica no. 139, 2008.

INESC. "Orçamento Quilombola 2008-2010 e a maquiagem na titulação". Nota Técnica no. 168, 2010.

MARIATEGUI, Jose Carlos. Por um socialismo indo-americano: ensaios escolhidos. Rio de Janeiro, Editora UFRJ, 2005.

MIGNOLO, Walter. Histórias Locais/Projetos Globais. Belo Horizonte, UFMG, 2003. 
QUIJANO, Aníbal. Colonialidade do poder e classificação social. In: SANTOS, Boaventura de Sousa; MENESE S, Maria Paula (Orgs.). Epistemologias do sul. Coimbra, Almedina, 2009.

SPIVAK, Gayatri. Pode o Subalterno Falar? Belo Horizonte: Editora da UFMG, 2010.

TAYLOR, Charles. Multiculturalismo: examinando a política de reconhecimento. Lisboa, Instituto Piaget, 1994.
TAYLOR, Charles. "O que é a agência humana?". In SOUZA, Jessé e Mattos, Patrícia (orgs.) Teoria Crítica no Século XXI. São Paulo, Annablume, 2007.

WALSH, Catherine. "Interculturalidade Crítica e Pedagogia decolonial: in-surgir, re-existir e re-viver". In Vera Maria Candau (org), Educação Intercultural na América Latina: entre concepçōes, tensões e propostas. Rio de Janeiro, Editora 7Letras, 2009.

\section{André Videira de Figueiredo}

Antropólogo e Sociólogo, Professor do Programa de Pós-Graduação em Ciências Sociais da UFRR, coordenador do Observatório de Povos Tradicionais (UFRRJ). 